Open Access

\title{
Donor antigen-primed regulatory $T$ cells permit liver regeneration and phenotype correction in hemophilia A mouse by allogeneic bone marrow stem cells
}

Veena Kochat ${ }^{1 *}$, Sumod Kanjirakkuzhiyil ${ }^{1}$, Prakash Baligar ${ }^{1}$, Perumal Nagarajan ${ }^{2}$ and Asok Mukhopadhyay ${ }^{1 *}$

\begin{abstract}
Introduction: Cell replacement therapy may be considered as an alternate approach to provide therapeutic dose of plasma factor VIII (FVIII) in patients with hemophilia A (HA). However, immune rejection limits the use of allogeneic cells in this mode of therapy. Here, we have examined the role of donor major histocompatibility complex (MHC)-stimulated host $\mathrm{CD}^{+} \mathrm{CD}_{25^{+}}$regulatory $T\left(\mathrm{~T}_{\text {reg }}\right)$ cells in suppressing immune responses against allogeneic uncommitted ( Lin $\left.^{-}\right)$bone marrow cells (BMCs) for correction of bleeding disorder in HA mice.

Methods: Allogeneic donor Lin ${ }^{-}$BMCs were co-transplanted with allo-antigen sensitized $T_{\text {reg }}$ cells in HA mice having acetaminophen-induced acute liver injury. Plasma FVIII activity was determined by in vitro functional assay, and correction of bleeding phenotype was assessed on the basis of capillary blood clotting time and tail-clip challenge. The immunosuppression potential of the sensitized $\mathrm{T}_{\text {reg }}$ cells on $\mathrm{CD}^{+} \mathrm{T}$ cells was studied both in vitro and in vivo. Suppression of inflammatory reactions in the liver against the homed donor cells by sensitized $T_{\text {reg }}$ cells was analysed by histopathological scoring. Allo-specificity of sensitized $T_{\text {reg }}$ cells and long-term retention of immunosuppression were examined against a third-party donor and by secondary challenge of allogeneic donor cells, respectively. The engraftment and phenotype change of donor BMCs in the liver and their role in synthesis of FVIII and liver regeneration were also determined.
\end{abstract}

Results: Co-transplantation of allogeneic Lin ${ }^{-}$BMCs with sensitized $T_{\text {reg }}$ cells led to systemic immune modulation and suppression of inflammatory reactions in the liver, allowing better engraftment of allogeneic cells in the liver. Allo-antigen priming led to allo-specific immune suppression even after 1 year of transplantation. Donor-derived endothelial cells expressed FVIII in HA mice, leading to the correction of bleeding phenotype. Donor-derived hepatocyte-like cells, which constitute the major fraction of engrafted cells, supported regeneration of the liver after acute injury.

Conclusions: A highly proficient FVIII secreting core system can be created in regenerating liver by transplanting allogeneic Lin ${ }^{-}$BMCs in HA mice where transplantation tolerance against donor antigens can be induced by in vitro allo-antigen primed $T_{\text {reg }}$ cells. This strategy can be beneficial in treatment of genetic liver disorders for achieving prophylactic levels of the missing proteins.

\footnotetext{
*Correspondence: veenak@nii.ac.in; ashok@nii.ac.in

'Stem Cell Biology Laboratory, National Institute of Immunology, Aruna Asaf Ali Marg, New Delhi 110067, India

Full list of author information is available at the end of the article
} 


\section{Introduction}

Hemophilia A (HA) is an X-linked autosomal recessive bleeding disorder in which factor VIII (FVIII) is inadequately synthesized. In humans, FVIII is found to be synthesized by liver sinusoidal endothelial cells (LSECs) [1]. Gene knockout studies have recently confirmed that endothelial cells (ECs) are the principal source of plasma FVIII $[2,3]$. In treatment of HA, gene replacement therapy showed initially encouraging results in life-long correction of HA in animal models [4-6], although the outcome of the phase I clinical trial was not conclusive; there was a gradual loss of its potency because of the formation of inhibitors [7]. As an alternative to gene therapy, transplantation of LSECs has shown encouraging therapeutic benefits in HA mice [8]. Owing to a profound shortage of transplantable donor LSECs, bone marrow cell (BMC) therapy is considered as an alternative for these patients. Attempts have been made to correct some genetic liver diseases by transplanting BMCs, which are capable of engrafting in the liver and replacing the parenchyma in the regenerating liver microenvironment and thereby produce prophylactic levels of missing proteins [9-12]. All of the above studies were based on transplantation of syngeneic BM-derived cells in mice with perturbed liver in which no humoral response to the missing proteins was observed.

Owing to intrinsic genetic defects, autologous cells cannot be used for therapeutic correction of HA. Immunosuppressants can be used to avoid rejection of donor cells but have serious side effects on long-term administration. $\mathrm{CD}_{4}^{+} \mathrm{T}$ cells of the recipient act as a doubleedged sword; they play a central role in rejection of allograft and are also involved in developing peripheral tolerance against the effector $T$ cells. A subpopulation of $\mathrm{CD} 4^{+} \mathrm{T}$ cells, known as regulatory $\mathrm{T}\left(\mathrm{T}_{\text {reg }}\right)$ cells, possesses immuno-modulatory properties that are capable of establishing transplant tolerance [13]. Thus, $\mathrm{T}_{\text {reg }}$ cells are considered a good candidate to overcome the rejection of allogeneic donor cells.

In this report, we have developed allo-antigen-specific $\mathrm{T}_{\text {reg }}$ cells of recipient background, which can improve the therapeutic benefit of allogeneic $\mathrm{Lin}^{-} \mathrm{BMCs}$ in HA mice. This strategy facilitates allo-specific immunosuppression, establishes transplant tolerance, and allows better engraftment of donor cells in the regenerating liver. The donor-derived cells helped in regeneration of the liver as well as in synthesis of FVIII protein that led to bleeding phenotype correction in HA mice.

\section{Methods}

\section{Animals}

Six- to eight-week-old HA mice [B6;129S4-F8 $\left.{ }^{\mathrm{tm} 1 \mathrm{Kaz}} / \mathrm{J}\right]$, $\mathrm{C} 57 \mathrm{Bl6} / \mathrm{J}$, enhanced green fluorescence protein (eGFP)-expressing Bl6/J [C57Bl6/J-Tg(UBCGFP) 30Scha/J], FVB/J,
eGFP-expressing FVB/J [FVB.Cg-Tg(CAGEGFP)B5Nagy/J], and $\mathrm{Balb} / \mathrm{c}$ mice were used in this study. Mice were obtained from The Jackson Laboratory (Bar Harbor, ME, USA) and maintained in individually ventilated cages and fed with autoclaved acidified water and irradiated food $a d$ libitum in the experimental animal facility of the institute. All experiments were conducted in accordance with procedures approved by the Institutional Animal Ethics Committee at the National Institute of Immunology.

\section{Flow cytometry}

Single-cell suspensions of BM, spleen, and liver were prepared $[14,15]$. Antibody staining of cells was performed at $4{ }^{\circ} \mathrm{C}$ for $30 \mathrm{~min}$. For biotinylated primary antibodies, the washed cells were further stained with fluorochrome-conjugated streptavidin or secondary antibodies. Cells were washed in phosphate-buffered salinebovine serum albumin (PBS-BSA) buffer and subjected to either analysis or sorting (FACS ArialII; BD Pharmingen, San Diego, CA, USA). The antibodies and conjugates used for the study were anti-CD4/biotin, antiCD25/PE, anti-Foxp3/AF647, Streptavidin/PerCP, and Streptavidin/APCCy7 (all from BD Pharmingen); anti$\mathrm{CD} 11 \mathrm{c} / \mathrm{PE}$ and anti-CD44/eFluor 450 (both from eBioscience, San Diego, CA, USA); and anti-CD31/biotin (BioLegend, San Diego, CA, USA).

\section{Donor antigen sensitized $\mathrm{T}_{\text {reg }}$ cells and characterization} $\mathrm{CD} 4{ }^{+} \mathrm{CD} 25^{+} \mathrm{T}_{\text {reg }}\left(\mathrm{nT}_{\text {reg }}\right)$ cells of HA mouse spleen were co-cultured with equal number of irradiated (1200 cGy) dendritic cells (DCs) of FVB/J mouse for $48 \mathrm{~h}$. The suppressive effect of $\mathrm{T}_{\text {reg }}$ cells on proliferation of $\mathrm{CD} 4^{+} \mathrm{T}$ cells was determined by carboxyfluorescein succinimidyl ester (CFSE) (Vybrant CFDA Cell Tracer kit; Invitrogen, Carlsbad, CA, USA) dilution assay, and interleukin-10 (IL-10) secretion was estimated by using enzyme-linked immunosorbent assay (eBioscience). In T-cell suppression assay, $\mathrm{CD} 4^{+} \mathrm{CD} 25^{-} \mathrm{T}$ cells were labeled with $5 \mu \mathrm{M}$ CFSE by incubating for $3 \mathrm{~min}$ at $37^{\circ} \mathrm{C}$. DCs from FVB/J mice $\left(1 \times 10^{5}\right.$ cells $)$ and CFSE-labeled $\mathrm{CD} 4^{+} \mathrm{CD} 25^{-} \mathrm{T}$ cells from HA mice $\left(1 \times 10^{5}\right.$ cells $)$ were taken in each well of 96-well round-bottom plate in triplicate. The $\mathrm{nT}_{\text {reg }}$ or $\mathrm{sT}_{\text {reg }}$ cells were added in each well at different ratios to $\mathrm{T}$ cells $(0,0.01,0.02,0.04,0.1,0.25,0.5$, and 1$)$ and cultured for 5 days. The dilutions of dye in viable CFSE-labeled cells were determined by flowcytometric analysis. Cellular viability was checked with 9 nM Sytox Red (S34859; Molecular Probes Inc., Eugene, OR, USA).

\section{Transplantation of cells and phenotypic correction}

$\mathrm{BM}$ progenitor cells ( $\mathrm{Lin}^{-} \mathrm{BMCs}$ ) were isolated from eGFP-expressing $\mathrm{FVB} / \mathrm{J}$ and Balb/c female mice following negative selection with MACS (Miltenyi Biotec, Gladbach, Germany). Acute liver injury was induced by 
administering acetaminophen $(500 \mathrm{mg} / \mathrm{kg}$ body weight) in male HA mice through intra-peritoneal injection. Within $30 \mathrm{~h}$ of liver injury, $0.25 \times 10^{6} \mathrm{Lin}^{-}$BMCs (eGFP) without or with $0.25 \times 10^{5} \mathrm{sT}_{\text {reg }} / \mathrm{nT}_{\text {reg }}$ cells were transplanted through tail vein injection. FVIII activity in plasma was measured by using a Coatest SP4 FVIII kit (Chromogenix; Instrumentation Laboratory SpA, Milan, Italy). Correction of bleeding phenotype was assessed by the tail-clip challenge test and whole blood clotting time. In the tail-clip challenge test, tails were clipped at a length of $1.5 \mathrm{~cm}$ without subsequent cauterization. Mice were observed for $24 \mathrm{~h}$, and percentage survival was noted. The whole blood clotting time was determined by drawing blood into a capillary tube from the retro-orbital plexus. The loaded capillary tube was broken at regular intervals starting from one end and slowly pulled apart to observe for fine strands of insoluble fibrin. Time taken to produce the visible clot was recorded.

\section{Liver histopathology}

Liver tissues were fixed in 10 \% buffered formalin. Paraffin sections were stained with hematoxylin and eosin. Histopathological abnormalities in the liver tissue sections were scored in accordance with a published protocol [16]. Histopathological scoring of inflammatory reactions are included in Additional file 1: Table S1.

\section{Immunostaining of cells/tissues}

Four percent paraformaldehyde-fixed cells were cytospined on poly-L-Lysine-coated glass slides. Liver tissue was frozen in tissue freezing medium (Jung; Leica Microsystems, Wetzlar, Germany), and 5- $\mu \mathrm{m}$ sections were cut. The cells or tissue sections were permeabilised with $0.1 \%$ saponin in PBS for $30 \mathrm{~min}$ and then blocked with $3 \%$ BSA solution for $1 \mathrm{~h}$. Samples were stained with primary antibodies overnight at $4{ }^{\circ} \mathrm{C}$, washed, and further stained with Alexafluor-conjugated secondary antibodies (Molecular Probes Inc.) at room temperature for $1 \mathrm{~h}$. Washed cells/sections were briefly treated with 4',6-diamidino-2-phenylindole (DAPI) $(10 \mu \mathrm{g} / \mathrm{ml})$ and mounted on glass slides by using ProLongR anti-fade (Molecular Probes Inc.). Antibodies used for immunostaining were anti-GFP (Clontech-Takara Bio Company, Kyoto, Japan), anti-CD31 biotinylated (BioLegend) antiFVIII(lc) (Santa Cruz Biotechnology Inc., Dallas, TX, USA), anti-albumin (Bethyl Laboratories Montgomery, TX, USA), and anti-Foxp3 and anti-F4/80 (eBioscience). Foxp3 staining was performed following DAB-HRP (3, 3'-diaminobenzidine-horseradish peroxidase) method (Vector Laboratories, Burlingame, CA, USA). The stained sections or cells were observed under an Olympus fluorescence microscope, and images were acquired by DP70 digital camera (Model IX51; Olympus, Tokyo, Japan) using LCPlanFl 20x and 60x objectives and Image Pro software (Media Cybernetics, Inc., Rockville, MD, USA). High-magnification images were taken with a Zeiss LSM 510 META confocal laser-scanning microscope (Carl Zeiss, Oberkochen, Germany) using a Plan-Apochromat $63 \times / 1.4$ oil objective with LSM 510 software for image acquisition and Zeiss LSM Image browser version 4.2.0.121 for processing. Relative cell fluorescence was measured by using ImageJ software (National Institutes of Health, Bethesda, MD, USA).

\section{Low-density lipoprotein uptake assay}

Low-density lipoprotein (LDL) uptake by ECs was assessed by fluorescence microscopy after incubation of the cells with $10 \mu \mathrm{g} / \mathrm{ml}$ acetylated LDL labeled with 1,19-dioctadecyl-3,3,39,39-tetramethylindo-carbocyanine perchlorate (DiI-Ac-LDL) (Molecular Probes Inc.) for $2 \mathrm{~h}$ at $37^{\circ} \mathrm{C}$.

\section{Gene expression}

Total RNA was isolated from purified cellular fractions by using TRI Reagent (Invitrogen), and cDNA was synthesized by using a High Capacity cDNA Reverse Transcription Kit (Applied Biosystems, part of Thermo Fisher Scientific Inc., Waltham, MA, USA). Real-time PCR was performed by using SYBR green technology (Applied Biosystems) in a Stratagene Mx3000P QPCR System (Agilent, Santa Clara, CA, USA). The primers used for the PCR are Gapdh (forward primer: 5'-ACGGCCG CATCTTCTTGTGCA-3', reverse primer: 5 '-CAGGCGC CCAATACGGCCAA-3') and FVIII (forward primer: $5^{\prime}$ GCCTGGGCTTA TTTCTC TGATG-3', reverse primer: 5'-TGAGCAGGATTCAGTGTGTTCG-3').

\section{Statistics}

Results of multiple experiments were reported as mean \pm standard error of the mean. Student's $t$ test was carried out to calculate the significance between the means of both groups, and a $P$ value of less than 0.05 was considered significant. All analyses were carried out by using GraphPad Prism software, version 5.02 (GraphPad Software, Inc., La Jolla, CA, USA).

\section{Results}

Allogeneic Lin $^{-}$BMCs protect HA mice from bleeding challenge in the presence of $s \mathrm{~T}_{\text {reg }}$ cells

Transplantation of allogeneic $\mathrm{Lin}^{-} \mathrm{BMCs}(\mathrm{FVB} / \mathrm{J})$ and $\mathrm{sT}_{\text {reg }}$ cells was performed in HA mice as in the scheme in Fig. 1a after inducing acute centrilobular necrosis in the liver, as presented in Additional file 2: Figure S1. Phenotype correction of the recipient mice was assessed after 3 months of transplantation. The HA mice used in the study contain neo sequence in the exon 16 of factor VIII A3 domain, so intact FVIII (lc) protein is not 


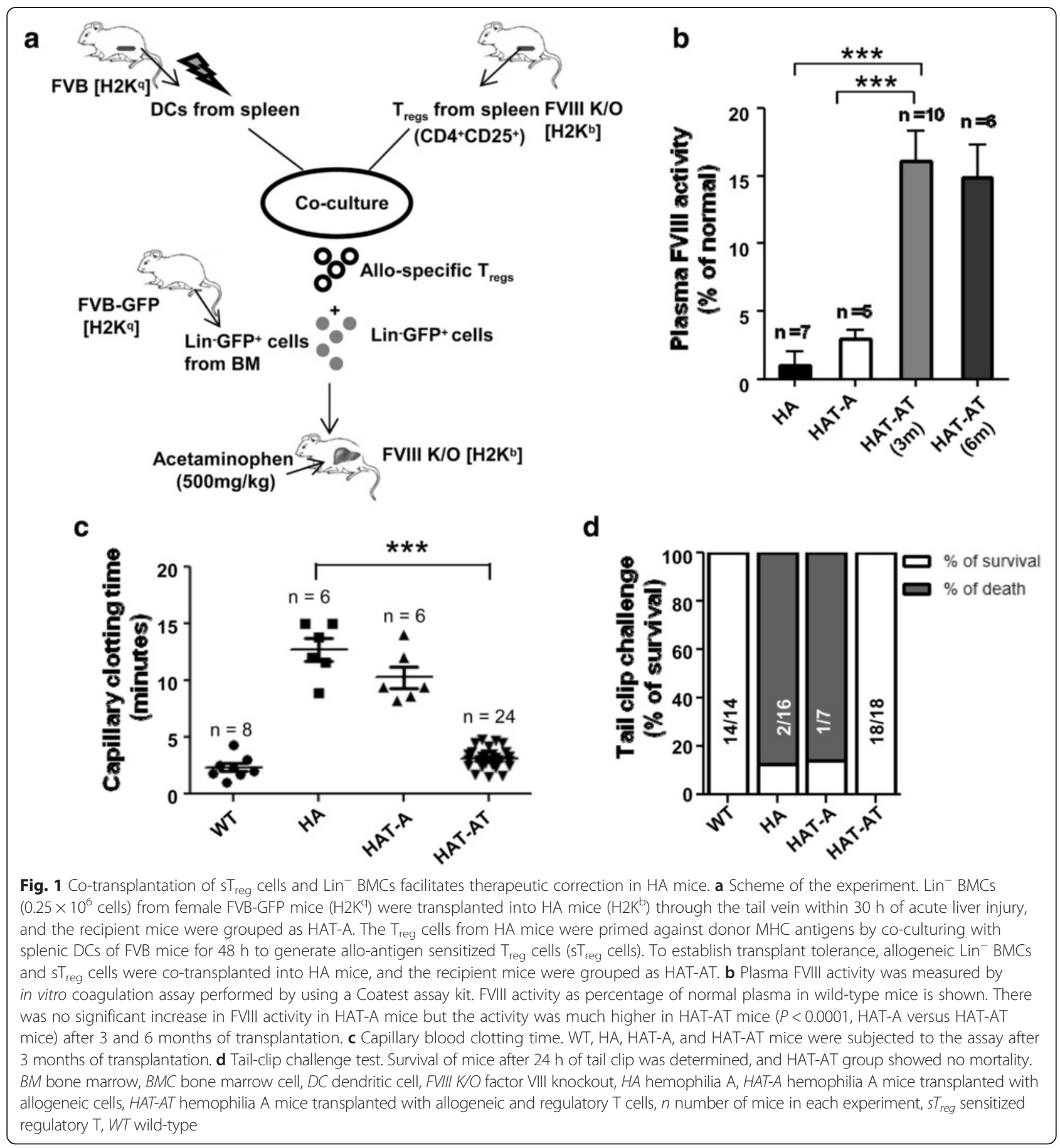

expressed [17]. The plasma FVIII activity in HAT-AT and HAT-A mice after 3 and 6 months of transplantation was determined by Coatest assay. The activity in HAT-A mice was marginally improved to $2.9 \pm 0.6 \%$, whereas a significant increase up to $16.1 \pm 2.2 \%$ of wildtype activity was obtained in HAT-AT mice (Fig. 1b). The plasma FVIII activity was retained even after 6 months of transplantation. The capillary blood clotting time in HAT-A mice was marginally decreased, whereas significant $(P<0.0001)$ reduction $(2.9 \pm 0.9$ against 12.9 $\pm 0.9 \mathrm{~min}$ ) was observed in the HAT-AT group as compared to HA mice (Fig. 1c). All 18 hemophilic mice that received allogeneic $\mathrm{Lin}^{-} \mathrm{BMCs}$ with $\mathrm{sT}_{\text {reg }}$ cells (HATAT) achieved hemostasis after the tail-clip challenge. In the HAT-A group, most of the mice died because of excessive bleeding within $24 \mathrm{~h}$ of the tail-clip, as did HA mice (Fig. 1d). Phenotype correction in the HAT-AT group implies adequate FVIII production in HAT-AT 
mice to activate the intrinsic coagulation pathway when compared to HAT-A and HA mice.

\section{$s T_{\text {reg }}$ cells exhibit enhanced regulatory effects than $\mathrm{nT}_{\text {reg }}$ cells on $\mathrm{T}$ cell proliferation in vitro}

In the above experiments, $\mathrm{sT}_{\text {reg }}$ cells were used because of robust regulatory properties as compared to $\mathrm{nT}_{\text {reg }}$ cells. To know which of the two regulatory cell types was more potent, we conducted T-cell suppression assay. Splenic $\mathrm{CD} 4{ }^{+} \mathrm{CD} 25^{+} \mathrm{T}_{\text {reg }}$ cells of HA mice were sensitized to alloDCs as before, and a proliferation assay was conducted by co-culturing CFSE-labeled $\mathrm{T}$ cells with different proportions of sensitized $\left(\mathrm{sT}_{\text {reg }}\right)$ and naïve $\left(\mathrm{nT}_{\text {reg }}\right)$ cells. The results showed a dose-dependent inhibition of T-cell proliferation by both regulatory cell types. The suppressive effect was pronounced $(P<0.001,0.05)$ with $\mathrm{sT}_{\text {reg }}$ cells at ratios of 0.1:1 up to 1:1 to T cells when compared to $\mathrm{nT}_{\text {reg }}$ cells (Fig. 2a, b). There was no significant change in Foxp3 expression in the $\mathrm{T}_{\text {reg }}$ cells on antigen priming, and more than $90 \%$ of the cells expressed the marker as in $\mathrm{nT}_{\text {reg }}$ cells, depicted in the dot-plots of Additional file 3: Figure S2.

As $T_{\text {reg }}$ cells also suppress proliferation of immune reactive $\mathrm{T}$ cells by secretion of cytokines like IL-10 and transforming growth factor-beta, we determined IL-10 level in the culture supernatants of the above experiments. Interestingly, both $\mathrm{nT}_{\text {reg }}$ and $\mathrm{sT}_{\text {reg }}$ cells secreted IL-10, but the quantity was significantly higher in $\mathrm{sT}_{\text {reg }}$ cells as compared to $\mathrm{nT}_{\text {reg }}$ cells (Fig. 2c). Hence, the above results suggest that priming of $\mathrm{T}_{\mathrm{reg}}$ cells with major histocompatibility complex (MHC) antigen of allogeneic DCs enhances their prospective regulatory effects on $\mathrm{T}$ cells during subsequent exposure of the same antigen.

\section{Allo-specific systemic immune modulation by $s \mathrm{~T}_{\text {reg }}$ cells in HAT-AT mice}

Time course analysis of $\mathrm{CD} 4^{+} \mathrm{CD} 25^{+} \mathrm{Foxp} 3^{+} \mathrm{T}_{\text {reg }}$ cells in the spleen of HAT-AT and HA-SC (sham control mice in which liver was damaged but neither $\mathrm{Lin}^{-} \mathrm{BMCs}$ nor $\mathrm{sT}_{\text {reg }}$ cells were transplanted) mice showed a significant increase in the percentage of $\mathrm{T}_{\text {reg }}$ cells in the HAT-AT group in comparison to the HAT-SC group of mice within the first 2 months of transplantation, and the percentages later became comparable (Fig. 3a). Furthermore, the percentage of splenic $\mathrm{CD} 4^{+} \mathrm{T}$ cells in HAT-A mice was $31.9 \pm 3.62 \%$, which significantly $(P<0.01)$ decreased to $17.13 \pm 1.15 \%$ in HAT-AT within 10 days of co-transplantation with $\mathrm{sT}_{\text {reg }}$ cells. Interestingly, this suppressive effect was continued throughout the course of the study (Fig. 3b). The above results suggest that effective immune suppression and development of tolerance are attributed to $\mathrm{sT}_{\text {reg }}$ cells.
To determine in vivo allo-specificity of $\mathrm{sT}_{\text {reg }}$ cells, an experiment was set up to compare $\mathrm{CD} 4^{+} \mathrm{T}$-cell activation by allogeneic donor $\mathrm{Lin}^{-}$BMCs from two different donor backgrounds $(\mathrm{Balb} / \mathrm{c}$ and $\mathrm{FVB} / \mathrm{J})$ in the presence of FVB-specific $\mathrm{sT}_{\text {reg }}$ cells. After 2 days of transplantation, the levels of antigen-experienced $\mathrm{CD} 4{ }^{+} \mathrm{CD} 44^{+}$activated $\mathrm{T}$ cells in the spleen were analysed, and the basal level in the spleen of normal mice was $0.95 \pm 0.07 \%$ (data not shown). We observed a significant $(P<0.05)$ reduction of activated $\mathrm{CD} 44^{+} \mathrm{CD} 44^{+} \mathrm{T}$ cells in the case of HAT-AT (FVB/J donor) as compared to HAT-A (FVB/J donor). In the parallel experiments, the suppression of T-cell activation against $\mathrm{Lin}^{-} \mathrm{BMCs}$ from Balb/c mice (third-party donor) was insignificant $(P=0.44)$ in the presence of FVB-specific $\mathrm{sT}_{\text {reg }}$ cells. There was a significant reduction in the levels of $\mathrm{CD} 4^{+} \mathrm{CD} 44^{+} \mathrm{T}$ cells in HAT-AT mice (FVB/J donor) when compared with HAT-AT mice (Balb/c donor) in the presence of FVBspecific $\mathrm{sT}_{\text {reg }}$ cells (Fig. 3c). These results indicate that $\mathrm{sT}_{\text {reg }}$ cells exhibit allo-specificity in vivo.

\section{$s \mathrm{~T}_{\text {reg }}$ cells suppress immune reactions in recipient liver} Examination of gross abnormalities in the liver, spleen, kidney, and lymph nodes of HAT-A and HAT-AT mice showed that inflammatory responses were largely exhibited only in the HAT-A group (Fig. 4a, b). The immune response against allograft can lead to infiltration of $\mathrm{T}$ cells into the graft site (in this case, the liver) and this may lead to persistent inflammatory reactions [18] that can result in cellular rejection. The extent of inflammatory response in the liver was ascertained by scoring various parameters [16] observed in HAT-A and HATAT mice (Fig. 4c and histopathological scorings mentioned in Additional file 1: Table S1) at various time intervals after transplantation. Among these, bile duct inflammation was rarely observed in our study. Histopathological scoring showed a significant decline of inflammatory reactions in the HAT-AT group when compared to the HAT-A group (Fig. 4d). These preliminary results indicate that $\mathrm{sT}_{\text {reg }}$ cells can circumvent inflammatory responses in the target site of engraftment, such as the liver in this case.

As migration of $\mathrm{T}_{\text {reg }}$ cells to the site of engraftment can confer protection to allograft against cytotoxic effects of infiltrating $\mathrm{T}$ cells, we examined their presence in different liver lobes. Morphometric analyses confirmed the presence of an average of six Foxp $3^{+}$cells per field in HAT-AT mice liver sections and this was significantly $(P<0.0001)$ higher than that in HAT-A mice (Fig. 5a). To determine the long-term immune suppression by $\mathrm{sT}_{\text {reg }}$ cells, after 1 year of transplantation, HAT-A and HAT-AT mice were given a second dose of $0.25 \times 10^{6}$ $\mathrm{Lin}^{-} \mathrm{BMCs}(\mathrm{FVB} / \mathrm{J}$ donor) after liver injury was induced. An intense inflammatory response was evidenced in the 
a
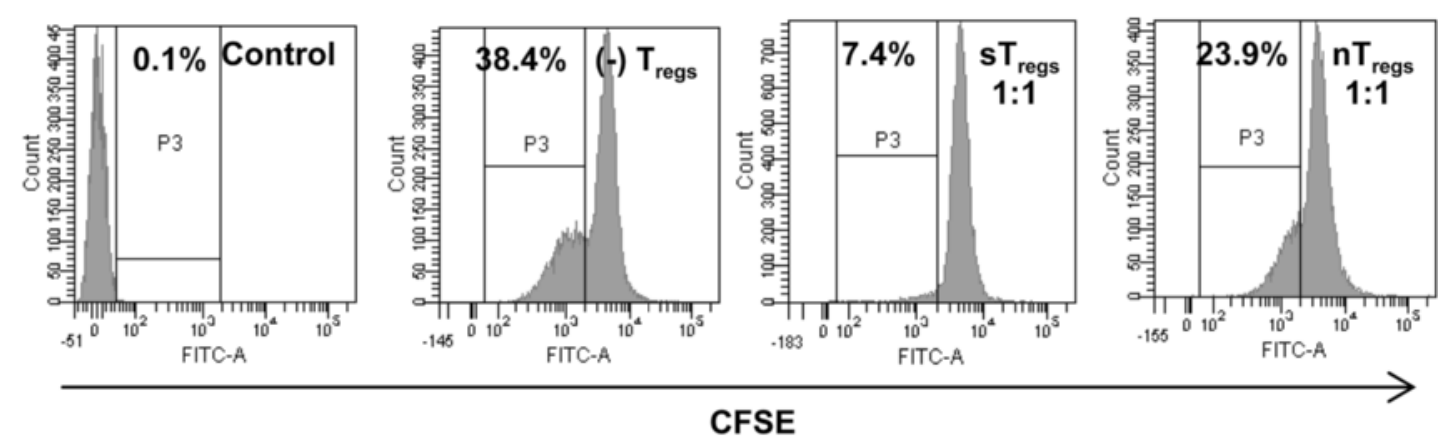

b

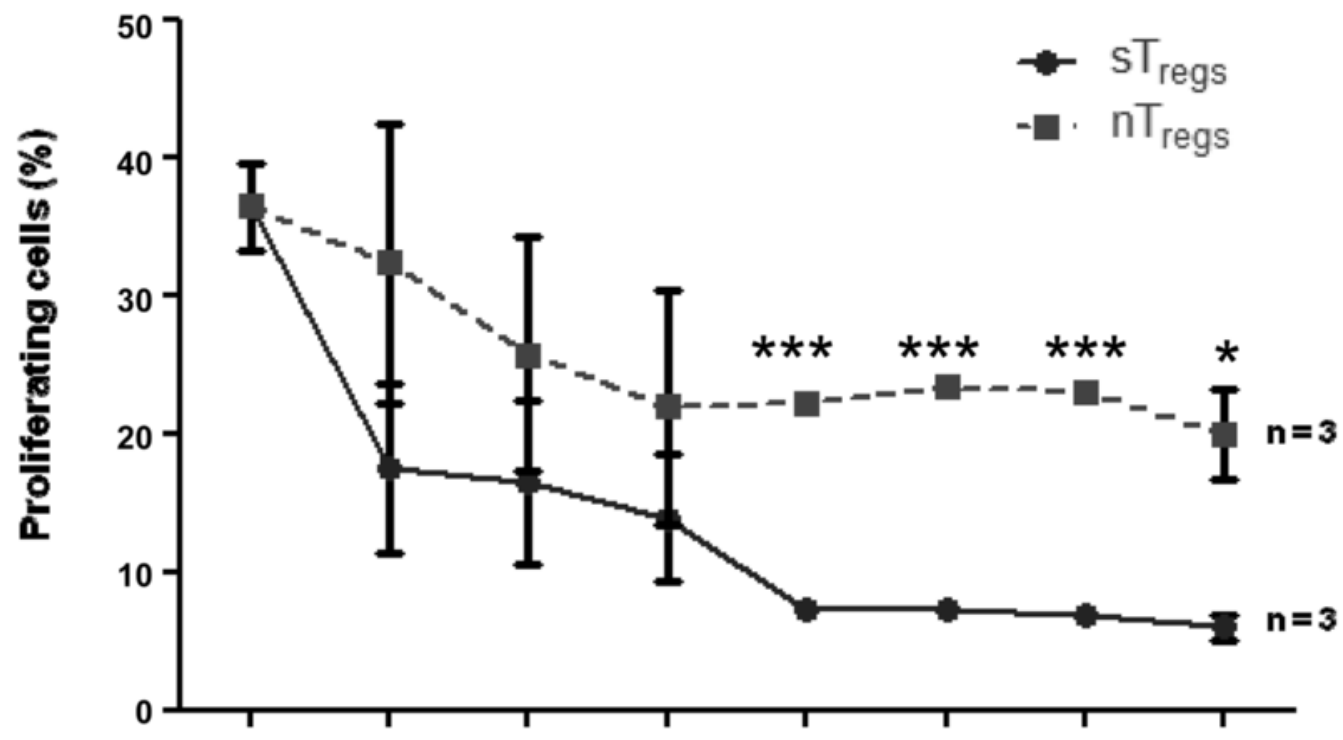

T cells $\left(5 \times 10^{5}\right.$ cells $)$ Allo-DCs $\left(5 \times 10^{5}\right.$ cells) $T_{\text {regs }}: T$ cells $0: 1 \quad 0.01: 1 \quad 0.02: 1 \quad 0.04: 1$

$0.1: 1$

$0.25: 1 \quad 0.5: 1$

$1: 1$

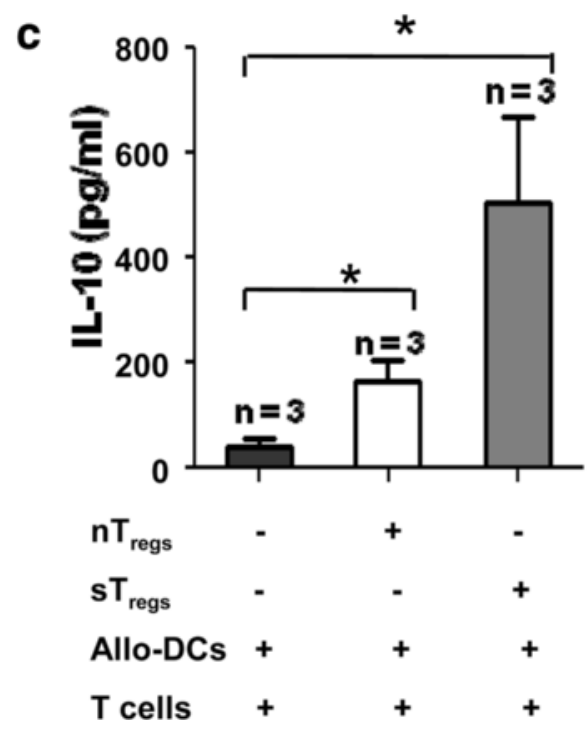

Fig. 2 (See legend on next page.) 
(See figure on previous page.)

Fig. 2 In vitro functional characterization of sT $_{\text {reg }}$ cells. a T-cell suppression (CFSE dilution) assay. DCs $\left(1 \times 10^{5}\right.$ cells) of FVB/J mice and $1 \times 10^{5}$ CFSE-labeled $\mathrm{CD}^{+} \mathrm{CD} 25^{-} \mathrm{T}$ cells (HA mice) were added to set up T-cell suppression assay. The $\mathrm{nT}_{\text {reg }}$ or $s \mathrm{~T}_{\text {reg }}$ cells were added in each well at different ratios of $\mathrm{T}$ cells and cultured for 5 days. The proliferation of T cells in mixed lymphocyte reaction was measured in terms of dilution of CFSE intensity as shown in the representative histograms. $\mathbf{b}$ A significant $\left({ }^{*} P=0.0142\right)$ difference in suppression of T-cell proliferation between two groups of $T_{\text {reg }}$ cells was noticed at 0.1:1, 0.25:1, 0.5:1, and 1:1 ratios of the regulatory to effector $T$ cells. $\mathbf{c} I L-10$ secretion in the culture supernatants ( $T_{\text {reg }}$ cells: T cells = 1:1) was measured by enzyme-linked immunosorbent assay. A significant increase in IL-10 levels was observed in cultures with $s T_{\text {reg }}$ cells $(P=0.04)$. CFSE carboxyfluorescein succinimidyl ester, DC dendritic cell, HA hemophilia A, IL-10 interleukin-10, $n$ number of experiments, $n T_{\text {reg }}$ naïve regulatory $T$, s $T_{\text {reg }}$ sensitized regulatory $T, T_{\text {reg }}$ regulatory $T\left({ }^{* *}\right) P<0.0001,\left(^{*}\right) P<0.05$

liver of HAT-A mice as compared to HAT-AT mice as shown in Fig. $5 \mathrm{~b}(P=0.05)$. The inflammatory score in HAT-AT mice after secondary challenge with allogeneic cells (Fig. 5b) was much higher than that observed in the earlier experiment (Fig. 4d) because of aging of mice and inflicting second time injury. These results indicate that immune suppression in the liver by $\mathrm{s}_{\text {reg }}$ cells can reduce the cellular responses involved in graft rejection even over a period of 1 year.

\section{Donor-derived endothelial cells are the major contributor of FVIII in HAT-AT mice}

Among the non-parenchymal cells, Lin $^{-}$BMCs were found to generate mainly CD31-expressing ECs (Fig. 6a). A few F4/80-expressing Kupffer cells (KCs) were also detected in the recipient liver (Fig. 6b). Earlier, it has been shown that in liver FVIII is synthesized primarily by LSECs but that a small amount can be synthesized by KCs. The contribution of donor cells to LSEC and KC fractions in HAT-AT mice liver was ascertained by flow cytometric analysis. It was revealed that $\mathrm{GFP}^{+}$donor cells constituted $2.6 \pm 0.64 \%$ of total non-parenchymal fraction, of which $2.02 \pm 0.42 \%$ was $\mathrm{CD} 31^{+} \mathrm{ECs}$ and $0.37 \pm 0.02 \%$ was $\mathrm{F} 4 / 80^{+}$macrophages/KCs (Fig. 6c). The time course analysis indicated that there was an increase of $\mathrm{GFP}^{+} \mathrm{CD} 31^{+} \mathrm{ECs}$ in the non-parenchymal fraction of the liver after initial engraftment; this is presented in the dot-plot analysis in Additional file 4: Figure S3. Further analysis of Ki67 antigen revealed that these donor-derived ECs also underwent proliferation along with host ECs. The percentages of proliferation of host and donor-derived ECs are shown in Additional file 5: Figure S4.

After 3 months of transplantation, FVIII expression in the liver of HAT-AT mice was analysed. The HA mice used in the study had a neo sequence in the exon 16 of factor VIII A3 domain preventing the synthesis of FVIII light chain (lc) protein and so primers were specifically designed against this region. Thus, amplification did not occur in HA mice samples, whereas FVIII(lc) expression was observed in wild-type and HAT-AT liver samples (Fig. 6d).

To decipher the role of donor-derived cells in correction of HA, we first analysed relative FVIII transcript levels in few specific liver non-parenchyma as well as $\mathrm{BMC}$ fractions of wild-type mice with respect to donor $\mathrm{Lin}^{-}$BMCs. Among all of the cell types analysed, LSECs apparently expressed the highest level of FVIII(lc) transcript, followed by $\mathrm{KCs}, \mathrm{CD} 45^{-}$(stromal cells), and

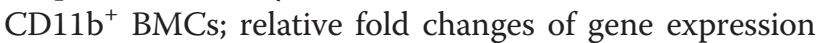
are depicted in Additional file 6: Figure S5. Next, BMderived cells $\left(\mathrm{GFP}^{+} \mathrm{CD} 31^{+}\right.$and $\left.\mathrm{GFP}^{+} \mathrm{F} 4 / 80^{+}\right)$were isolated from the liver of HAT-AT mice and immunocytochemically analysed for the expression of FVIII(lc) protein. As shown in Fig. 6e, LSECs isolated from HA mice did not express FVIII(lc) protein, whereas wildtype LSECs and ECs isolated from HAT-AT mice express the same. A similar trend was observed in wildtype $\mathrm{KCs}$ and $\mathrm{eGFP}^{+} \mathrm{F} 4 / 80^{+}$cells, isolated from HAT-AT mice liver, but the expression level was much lower. To compare FVIII(lc) protein expression in liver resident LSECs and KCs (in wild-type mice) with BM-derived ECs and KCs (in HAT-AT mice), we have determined relative fluorescence intensity of the protein by ImageJ software. It was apparent that FVIII(lc) protein level was significantly high in both LSECs and BM-derived ECs but much lower in KCs (Fig. 6e, bar diagram). On the basis of above results, we propose that BM-endothelial progenitor cells were converted into FVIII-expressing LSEC-like cells in the recipient mice liver. To prove that LSECs and BM-derived ECs were functionally similar, we conducted an LDL uptake study; the results revealed that LDL uptake was comparable, as presented in Additional file 7: Figure S6. To confirm that engrafted BM-derived ECs in liver synthesized FVIII, we conducted immunohistochemistry analysis in HAT-AT liver sections after 4 months of transplantation. The results clearly demonstrate that $\mathrm{GFP}^{+} \mathrm{CD} 31^{+}$cells expressed FVIII (Fig. 6f). These results suggest that transplantation of $\mathrm{Lin}^{-} \mathrm{BMCs}$ causes phenotype correction in HA mice because of the synthesis of FVIII by BM-derived ECs.

\section{$s \mathrm{~T}_{\text {reg }}$ cells support allogeneic BMC-mediated liver regeneration and functional improvement}

Transplant tolerance generated by $\mathrm{sT}_{\text {reg }}$ cells can improve engraftment of donor cells in the liver. So liver sections of HAT-A and HAT-AT mice were analysed for engraftment of eGFP-expressing donor cells after 


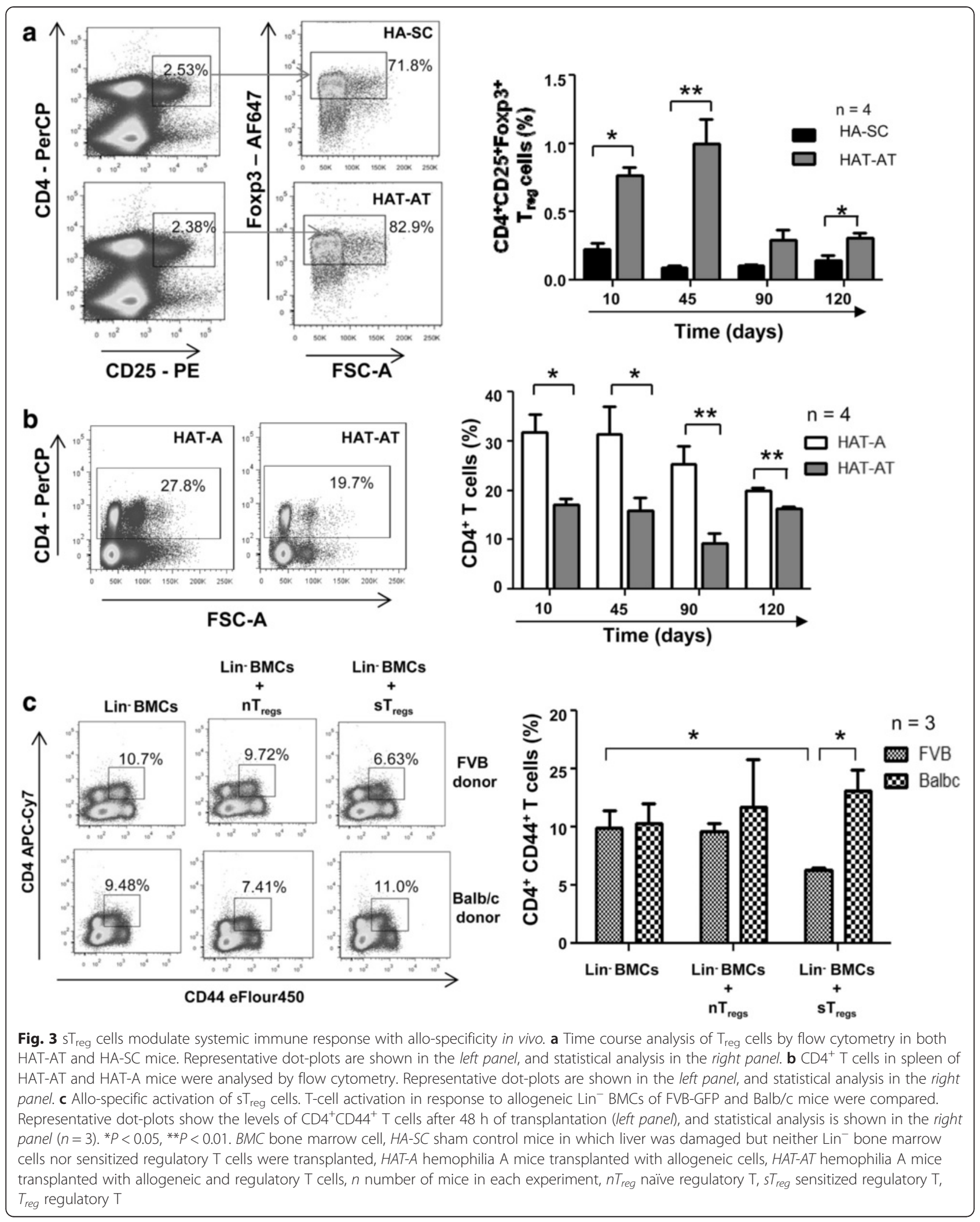




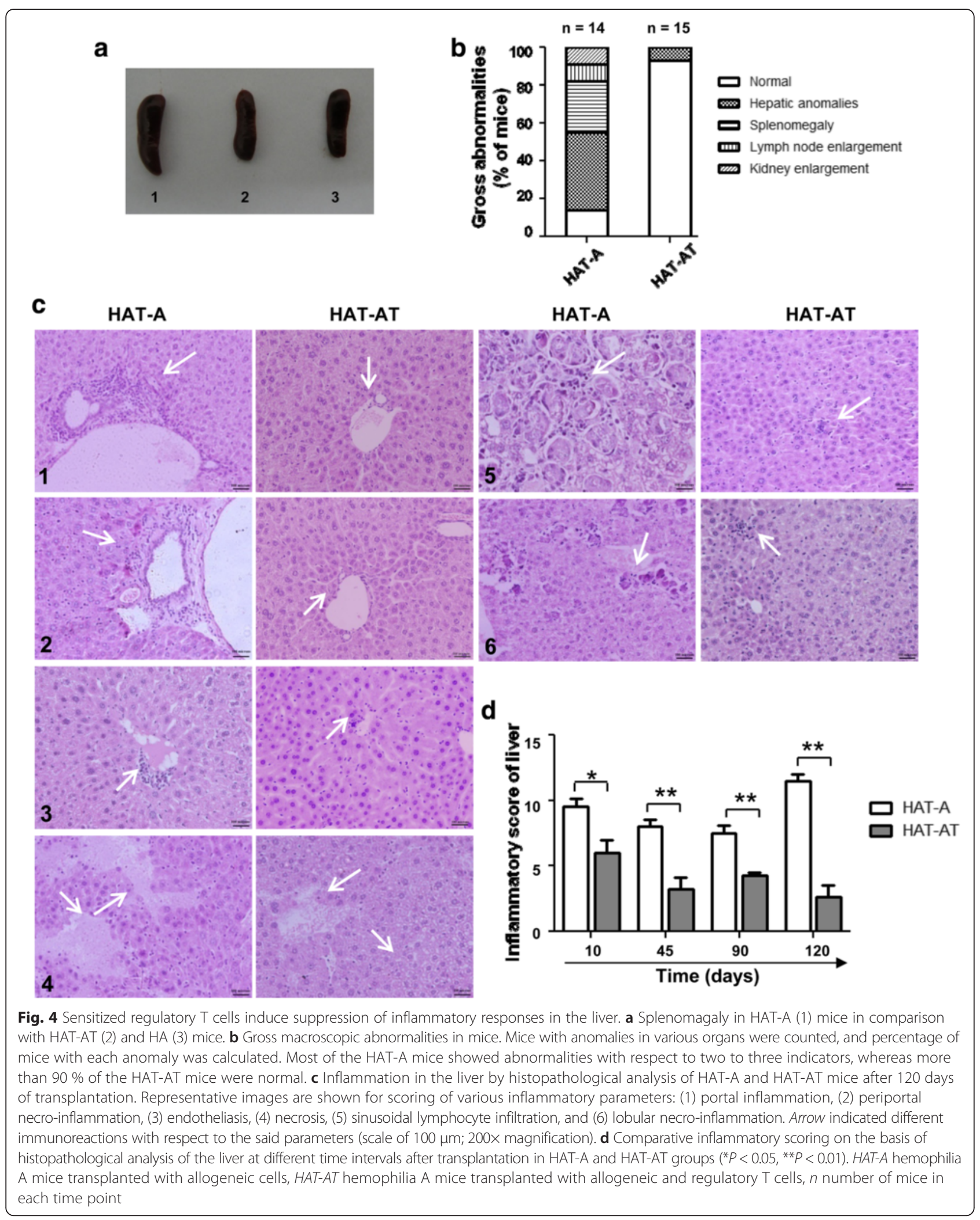



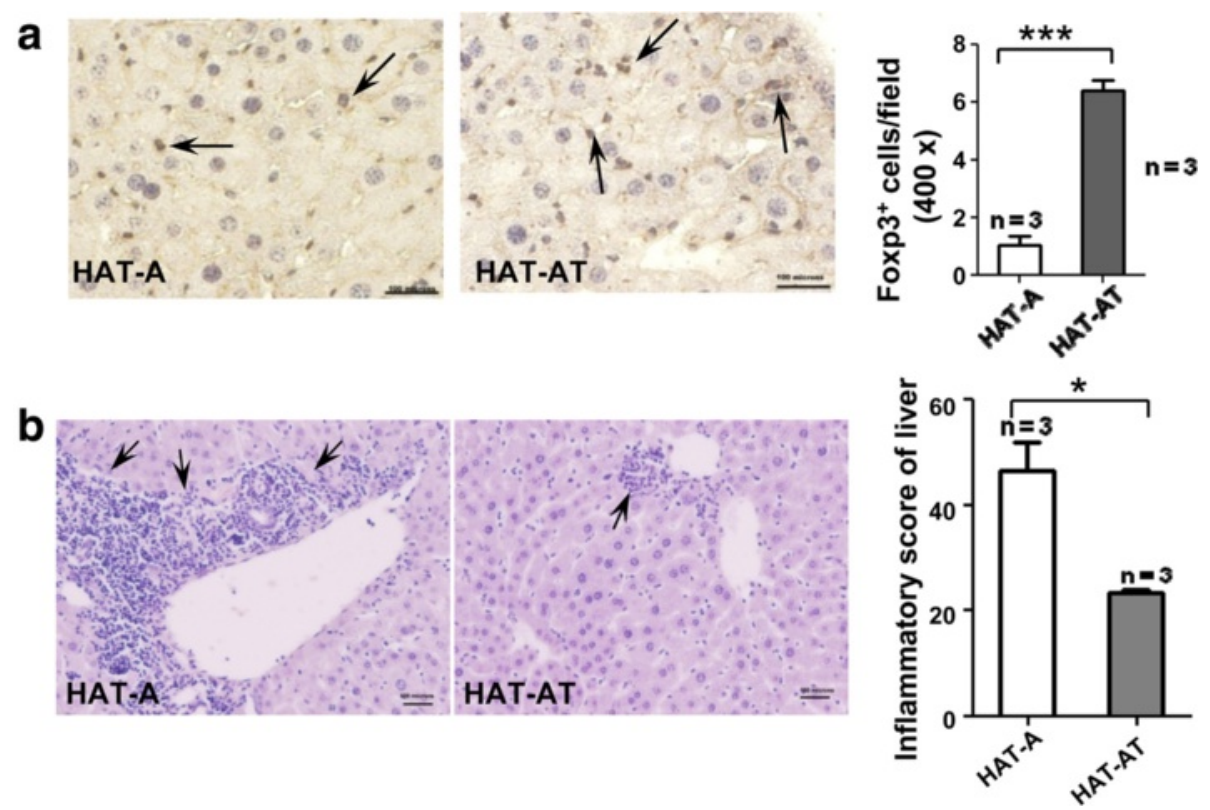

Fig. 5 Long-term retention of transplant tolerance. a Migration of regulatory T cells to the liver. Representative photomicrographs show Foxp3-expressing cells (left panel, arrows) after 3 months of transplantation (scale of $100 \mu$ m; 400x magnification). Statistical analysis is shown in the right panel. b After 1 year of primary transplantation, a second dose of allogeneic $0.25 \times 10^{6} \mathrm{Lin}^{-}$BMCs from FVB-GFP cells was given to HAT-A and HAT-AT mice after liver injury was inflicted. Representative photomicrographs show extensive immune reactions in HAT-A mice (scale of $100 \mu$ m; 200x magnification). Statistical analysis of inflammatory scores determined on the basis of histo-pathological analysis of liver is shown in the right panel. BMC bone marrow cell, HAT-A hemophilia A mice transplanted with allogeneic cells, HAT-AT hemophilia A mice transplanted with allogeneic and regulatory T cells, $n$ number of mice in each experiment (**) $P<0.0001$, ( $\left.^{*}\right) P<0.05$

4 months of transplantation. Immunohistochemical analysis of recipient liver sections showed that, owing to suppression of immune response, engraftment of more allogeneic BMCs occurred in HAT-AT mice liver as compared to HAT-A (Fig. 7a). Morphometric analysis based on 30 non-overlapping fields in each set of mice showed that the percentage of $\mathrm{GFP}^{+}$cells in HAT-AT liver was $7.27 \pm 0.82 \%$, which is significantly higher $(P<0.0001)$ than that in HAT-A liver (Fig. $7 \mathrm{a}$, bar diagram). On further analysis, it was found that many donor-derived cells expressed albumin and attained morphology similar to that of hepatocytes (Fig. 7b). Morphometric analyses of images (200× magnification) in 20 different fields of liver sections per mouse after 45 and 120 days of transplantation showed that $5.26 \pm 0.88 \%$ and $7.57 \pm 0.47 \%$ cells, respectively, were eGFP-expressing. The percentages of donor-derived albumin-expressing cells in these two time points were $4.72 \pm 0.87 \%$ and $5.72 \pm 0.5 \%$, respectively (Fig. $7 c$, bar diagram).

Since donor-derived cells increased in their number, we were interested to know how long they can multiply. So liver sections were co-stained for eGFP and Ki67 antigens after 45 and 120 days of transplantation. It was revealed that some donor-derived cells that morphologically resembled hepatocytes underwent proliferation in the 45th day samples, but no Ki67 staining was observed in the liver after 120 days of transplantation (Fig. 7d). As the donor-derived hepatocytes stopped proliferation in a later time point, we concluded that liver regeneration was completed.

Acute liver injury due to administration of toxic doses of acetaminophen results in increased serum alanine aminotransferase (ALT) and aspartate aminotransferase (AST) levels. These serum parameters were gradually normalized during liver regeneration. Owing to persistent inflammatory reactions for chronic rejection, the serum AST and ALT levels were maintained significantly high in HAT-A mice even after 90 days of transplantation. As expected, they decreased to normal levels in HAT-AT mice by this period (Fig. 7e, f).

\section{Discussion}

In developed countries, factor replacement therapy is readily available, but owing to high prophylactic treatment cost, many patients are still treated on demand. The patients in the developing countries, owing to extreme financial constraint, are treated mostly on demand [19]. So a permanent solution for HA has been sought for quite some time. Gene therapy appears to be promising as a small increase in plasma factor levels can essentially improve the clinical outcome of HA [20]. Clinical studies have shown that $10-40 \%$ of patients with the 


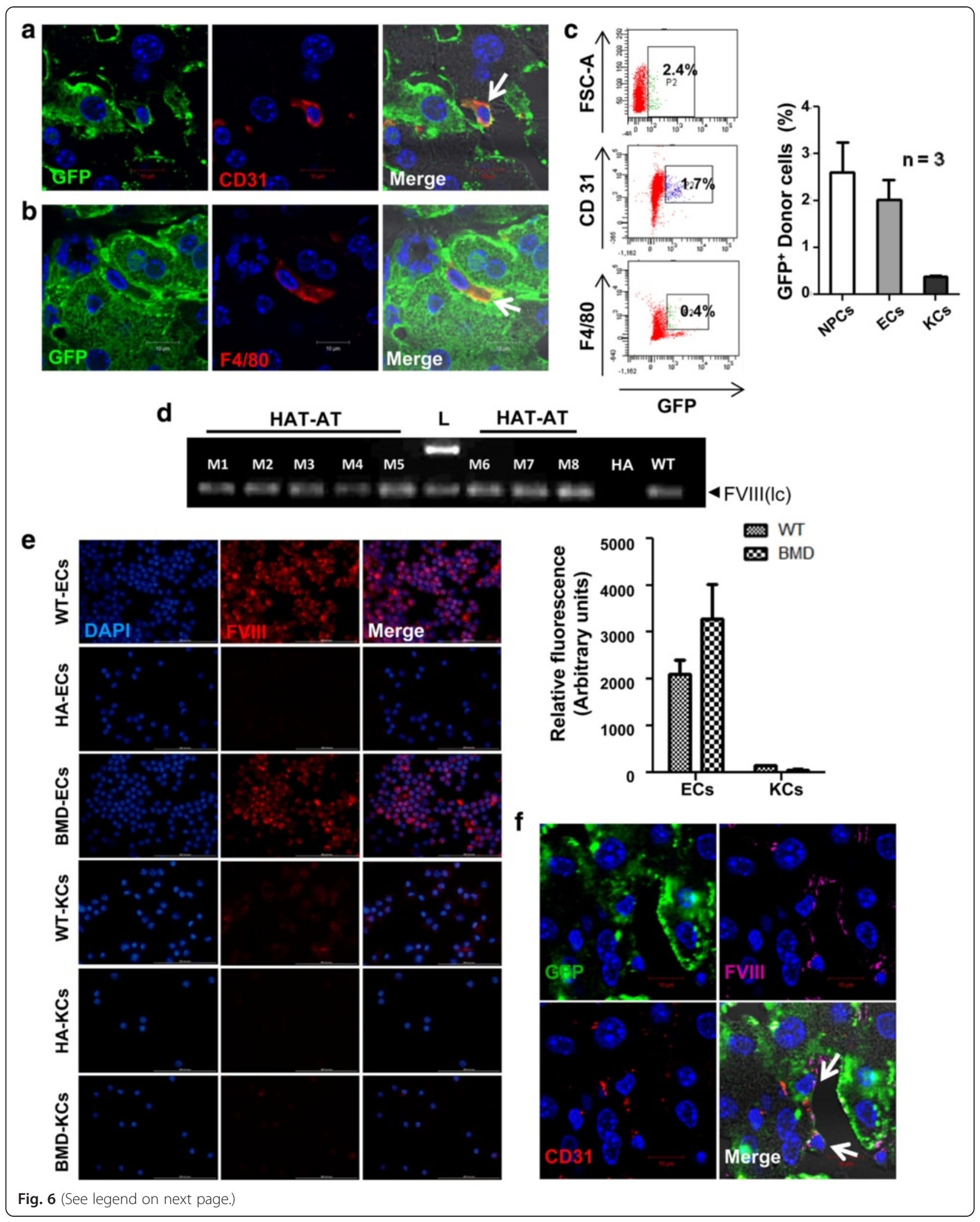




\section{(See figure on previous page.)}

Fig. 6 FVIII synthesis by donor-derived endothelial cells and Kupffer cells in HAT-AT liver. a Donor-derived endothelial cells indicated by white arrow (anti-GFP/donkey anti-mouse Alexa fluor 488 and anti-CD31/donkey anti-rat Alexa fluor 594) in HAT-AT liver (scale of $10 \mu \mathrm{m} ; 630 \times 2.8$ zoomed magnification). b Donor-derived Kupffer cells indicated by white arrow (anti-GFP/donkey anti-mouse Alexa fluor 488 and anti-F4/80/donkey anti-rat Alexa fluor 594) in HAT-AT liver (scale of $10 \mu \mathrm{m} ; 630 \times 2.8$ zoomed magnification). c Flow cytometric analysis of donor cells in non-parenchymal fraction of HAT-AT mouse liver after 1 month of transplantation. Representative dot-plots are given in the left panel, and quantitative analysis is shown in the right panel $(n=3)$. d FVIII(IC) gene expression in livers of HAT-AT, HA, and WT mice. e Immunocytochemical analysis of FVIII in endothelial and Kupffer cells from HA, WT, and HAT-AT mice (scale of $100 \mu \mathrm{m} ; 600 \times$ magnification). Relative cell fluorescence intensities are shown in the bar diagram on right. $\mathbf{f}$ Highly magnified confocal images (scale of $10 \mu \mathrm{m} ; 630 \times 2.8$ zoomed magnification) show that donor-derived endothelial cells express FVIII indicated by white arrow (anti-GFP/donkey anti-mouse Alexafluor 488, anti-CD31/donkey anti-rat Alexafluor 594, anti-FVIII(Ic)/donkey anti-rabbit Alexafluor 647). BMD bone marrow derived, DAPI 4',6-diamidino-2-phenylindole, EC endothelial cell, GFP green fluorescent protein, FVIII factor VIII, FVIII(IC) factor VIII light chain, HA hemophilia A, HAT-AT hemophilia A mice transplanted with allogeneic and regulatory T cells, KC Kupffer cell, $n$ number of mice in each experiment, NPC non-parenchymal cell, WT wild-type

severe form of HA develop inhibitors and thus treatment fails in the long run [21]. In humans, the primary source of plasma FVIII is LSECs [1-3]; however, the same has been found to be synthesized in low quantities by mesenchymal stem cells (MSCs) [22, 23] and macrophages [23].

Various cell-based therapies have been advocated for the treatment of HA in experimental animals, and in all cases therapeutic correction levels of plasma FVIII were achieved. Previously, we showed that syngeneic BMderived uncommitted cells can synthesize FVIII and confer protection against bleeding to death [12, 24]. Here, we have identified three different cell types-ECs, $\mathrm{KCs}$, and hepatocytes - that can originate from allogeneic Lin' BM-derived cells in recipient mouse liver. Interestingly, we observed that FVIII synthesis occurred primarily in BM-derived ECs. Owing to the shortage of cadaver livers, therapeutic correction of HA by transferring healthy LSECs [8] may not be feasible. $\mathrm{Lin}^{-} \mathrm{BMCs}$ contain endothelial progenitors $[25,26]$; so we propose that these can ultimately differentiate into functional LSECs [27] and produce FVIII. Lin ${ }^{-}$BMCs also consist of MSCs, which can participate directly in liver regeneration by secreting factors that help in tissue repair, modulation of inflammatory responses, and activation of hepatic progenitor cells [28]. An earlier report suggested that BM-MSCs and mononuclear cells in peripheral blood secrete FVIII and can act as a supporting system to deliver FVIII at the bleeding sites [23]. Even though MSCs can express FVIII protein [22], they have been used for short-term transplantation study of phenotype conversion in HA mice [23].

Our study confirmed the majority of BM-derived cells as hepatocyte-like cells, as a substantial fraction of necrosed hepatocytes were replaced by them [12]. Even though BM-derived hepatocytes have been reported in liver regeneration $[12,29,30]$, the plasticity of BM stem cells had been questioned by many groups. The general belief is that cell fusion is the principal mechanism for generation of BM-derived hepatocytes [31-34]. Even if BMCs assume hepatic phenotype by fusion followed by ploidy reduction or by direct differentiation, our approach still has a high clinical relevance in the context of liver regeneration using allogeneic BMCs. In acetaminophen-induced liver injury, we observed that donor cells were engrafted mostly in the liver rather than in the BM or spleen ( 0.1\%). In contrast, in the case of a radiation-induced injury model, substantial fractions of BMCs are found to be engrafted in the BM and spleen because of their natural niches. Thus, we conclude that Lin $^{-}$BMCs may act as an ideal source of cells for liver regeneration in HA mice.

A highly competent core system involving FVIIIexpressing LSECs is more desirable so that repeated infusion of purified FVIII will not be required. Moreover, since liver is an immune-privileged organ, the engrafted $\mathrm{Lin}^{-}$BMCs can facilitate long-term management of the disease. In the present model, transplantation of $\mathrm{Lin}^{-}$ BMCs into HA mice restored plasma FVIII activity well above the therapeutic correction level $(\leq 10 \%$ normal activity). Another unique advantage was that no FVIII inhibitor was detected in our earlier study using the same cells but from a syngeneic source [12]. Anti-FVIII antibody (inhibitor) formation in the long run occurs both in cases of recombinant and plasma-derived FVIII therapy and in the experimental FVIII gene therapy model [7], which urged for alternate immunological approaches to prevent these humoral responses [35-37]. We propose that in perturbed liver a fraction of the damaged hepatocytes, LSECs, and KCs are replaced by BM-derived cells. High expression of FVIII by BM-derived ECs suggests that endothelial progenitor cells of the BM might have differentiated into liver-specific endothelial-like cells. We observed relatively high expression of FVIII by these cells as compared with wild-type LSECs and this may be due to high selection pressure in HA mice for the synthesis of FVIII. This could explain why plasma FVIII activity in HAT-AT mice was not commensurate with the number of BM-derived ECs engrafted in the liver.

As hemophilia is a genetic disease, autologous cells cannot be used for treatment unless they are genetically modified to express the desired protein. After allogeneic transplantation, the host $\mathrm{T}$ lymphocytes upon activation 


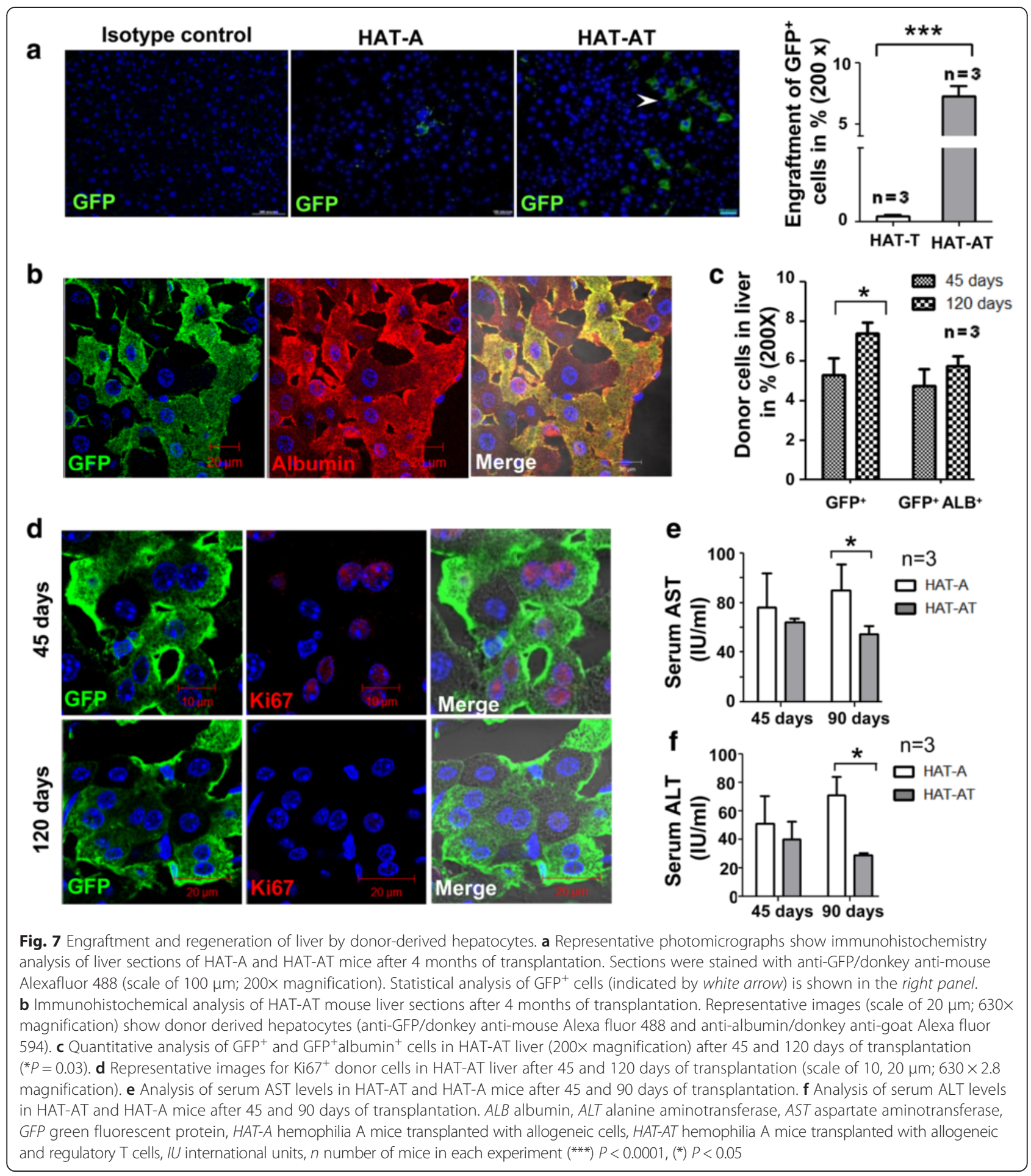

with donor antigens acquire effector functions and destroy the donor cells as was evidenced by low retention of donor cells in HAT-A mice. Allo-graft rejection is mediated by three effector pathways: (a) delayed-type hypersensitivity (DTH) reactions by allo-antigen activated $\mathrm{CD}^{+} \mathrm{T}$ cells, (b) activation of $\mathrm{CD} 8^{+}$cytotoxic $\mathrm{T}$ lymphocytes, and (c) antibody-mediated. Since the liver is the major site for engraftment of the allogeneic $\mathrm{Lin}^{-} \mathrm{BMCs}$, inflammatory reactions were pronounced in the liver. The T-cell response was evidenced by low retention of donor cells in HAT-A mice. In this study, we examined the response of $\mathrm{CD}^{+}{ }^{+} \mathrm{T}$ cells to $\mathrm{MHC}$ antigens on allogeneic donor cells and their suppression by establishing peripheral tolerance using $\mathrm{T}_{\text {reg }}$ cells. We have demonstrated that 
$\mathrm{sT}_{\text {reg }}$ cells can suppress immune responses against allogeneic BMCs by reducing inflammatory response in the liver, thus leading to better engraftment of cells. Our finding concurred with other reports in which allo-antigenspecific $\mathrm{T}_{\text {reg }}$ cells improved peripheral tolerance to $\mathrm{BM}$, skin, and cardiac allo-grafts [38, 39].

During sensitization, $\mathrm{T}_{\text {reg }}$ cells were primed against $\mathrm{MHC}$ molecules of the donor cells. In the host, these $\mathrm{sT}_{\text {reg }}$ cells, through linked suppression, not only recognize a single allo-antigen exposed during in vitro sensitization but also can suppress immune responses against most allo-antigens expressed by the graft [40]. These activated $\mathrm{T}_{\text {reg }}$ cells in circulation can also induce secondary regulatory phenotype in circulatory $\mathrm{T}$ cells by infectious tolerance and generate induced $\mathrm{T}_{\text {reg }}$ cells, which can further lead to effective immune suppression during the rejection phase [41]. Furthermore, we conclude that contactindependent mechanisms were also responsible for controlling immune response as IL-10 was detected in T-cell proliferation assay [42, 43]. Another benefit of adoptive transfer of in vitro antigen primed $\mathrm{T}_{\text {reg }}$ cells was that their suppressive effects were comparatively antigen-specific as no significant activation of $\mathrm{CD}_{4}^{+} \mathrm{T}$ cells was observed when $\mathrm{sT}_{\text {reg }}$ cells were co-transplanted with third-party donor Lin $^{-}$BMCs. Not only that, our preliminary results suggested retention of peripheral tolerance for long duration with a single dose of $\mathrm{sT}_{\text {reg }}$ cells. The presence of significantly higher numbers of $T_{\text {reg }}$ cells in recipient liver proved that either $\mathrm{s}_{\text {reg }}$ cells or induced $\mathrm{T}_{\text {reg }}$ cells, derived from $\mathrm{T}$-cell pool, or both can migrate to the primary site of inflammation to prevent rejection of allogeneic cells. Long-term management of HA by the synthesis of prophylactic levels of FVIII by donor-derived cells can overcome the requirement for repeated infusion of FVIII in clinical settings. Furthermore, this approach will allow us to overcome biosafety issues pertaining to gene therapy. In future adoptive transfer of donor $\mathrm{MHC}$, primed $\mathrm{T}_{\text {reg }}$ cells may substitute for the use of immunosuppressive drugs in case of transplantation of allogeneic cells. If the present approach has to be experimented in higher animal models of HA like Chapel Hill dogs, a pre-conditioning regimen of FVIII is recommended to protect the recipient against initial hemorrhage while inducing partial liver injury. Our preliminary results suggests that $\mathrm{T}_{\text {reg }}$ cells can be taken from the recipient and primed against donor antigens and expanded in vitro to obtain enough cells for exerting immune suppressive effects. Besides establishing a pre-conditioning FVIII regimen, further studies need to be pursued on long-term retention of allo-specificity of these primed $\mathrm{T}_{\text {reg }}$ cells before bench-to-bedside translation.

\section{Conclusions}

Our report establishes that transfer of allo-antigen primed $\mathrm{T}_{\text {reg }}$ cells along with allogeneic $\mathrm{Lin}^{-}$BMCs in a liver regeneration model of HA mice allows engraftment of BM-derived endothelial progenitor cells in liver, synthesis of FVIII by donor-derived cells, and subsequent correction of bleeding phenotype. Engraftment of allogeneic cells in the liver was possible because of systemic immune suppression and reduction in inflammatory reactions in the liver, the latter of which promotes generation of alloantigen-specific transplantation tolerance. Furthermore, donor BM-derived hepatocytes play an important role in regeneration of injured liver parenchyma.

\section{Additional files}

\begin{abstract}
Additional file 1: Table S1. Histopathological scoring of inflammatory reactions in liver of transplanted mice. HAT-A hemophilia A mice transplanted with allogeneic cells, HAT-AT hemophilia A mice transplanted with allogeneic and regulatory $T$ cells. (DOC 60 kb)

Additional file 2: Figure S1. Histopathology of liver sections after $24 \mathrm{~h}$ of acetaminophen-induced injury. (TIFF $1189 \mathrm{~kb}$ )

Additional file 3: Figure S2. Expression of Foxp3 in naïve ( $n T_{\text {reg }}$ ) and allo-sensitized ( $\mathrm{sT}_{\text {reg }}$ ) regulatory $\mathrm{T}$ cells. (TIFF $523 \mathrm{~kb}$ )

Additional file 4: Figure S3. Donor-derived non-parenchymal cells in HAT-AT liver. a Time course analysis of GFP ${ }^{+}$donor cells in nonparenchymal cells of HAT-AT mice. $\mathbf{b}$ Time course analysis of GFP ${ }^{+}$ donor-derived endothelial cells in non-parenchymal cells of HAT-AT mice. GFP green fluorescence protein, HAT-AT hemophilia A mice transplanted with allogeneic and regulatory T cells. (TIFF 643 kb)

Additional file 5: Figure S4. Proliferation of endothelial cells in HAT-AT liver after 5 and 10 days of transplantation. Proliferating cells $\left(K i 67^{+}\right)$were found to be present in both host and donor-derived fractions of endothelial cells. HAT-AT hemophilia A mice transplanted with allogeneic and regulatory $T$ cells. (TIFF $733 \mathrm{~kb}$ )
\end{abstract}

Additional file 6: Figure S5. Expression of FVIII mRNA in liver and bone marrow cells of wild-type mice. Fold change calculated with respect to expression in Lin ${ }^{-}$BMCS. BMC bone marrow cell, FVIII factor VIII, LSEC liver sinusoidal endothelial cell. $\left.{ }^{*}\right) P<0.05$. (TIFF $183 \mathrm{~kb}$ )

Additional file 7: Figure S6. Dil-AC-LDL $\left(^{*}\right) P<0.05$ uptake in WT LSECS and donor BMD ECs from HAT-AT liver. BMD-EC bone marrow-derived endothelial cell, Dil-AC-LDL 1,19-dioctadecyl-3,3,39,39-tetramethylindocarbocyanine perchlorate, HAT-AT hemophilia A mice transplanted with allogeneic and regulatory T cells, WT LSEC wild-type liver sinusoidal endothelial cell. (TIFF 491 kb)

\section{Abbreviations}

ALT: Alanine aminotransferase; AST: Aspartate aminotransferase; BM: Bone marrow; BMC: Bone marrow cell; BSA: Bovine serum albumin; CFSE: Carboxyfluorescein succinimidyl ester; DC: Dendritic cell; EC: Endothelial cell; eGFP: Enhanced green fluorescent protein; FVIII: Factor VIII; FVIII(IC): Factor VIII light chain; HA: Hemophilia A; HAT-A: Hemophilia A mice transplanted with allogeneic cells; HAT-AT: Hemophilia A mice transplanted with allogeneic and regulatory T cells; IL-10: Interleukin-10; KC: Kupffer cell; LDL: Low-density lipoprotein; LSEC: Liver sinusoidal endothelial cell; MHC: Major histocompatibility complex; MSC: Mesenchymal stem cell; $n T_{\text {reg: }}$ Naïve regulatory T; PBS: Phosphate-buffered saline; $P C R$ : Polymerase chain reaction; $S T_{\text {reg }}$ : Sensitized regulatory $T ; T_{\text {reg: }}$ : Regulatory $T$.

\section{Competing interests}

The authors declare that they have no competing interests.

\section{Authors' contributions}

VK contributed to conception and design of experiments; performed all transplantation experiments, in vitro and in vivo characterization of $\mathrm{T}_{\text {reg }}$ cells, molecular and cellular analyses, FVIII assay and functional tests, and histopathology; analysed and interpreted data; and wrote the manuscript. SK 
designed and performed some $T_{\text {reg }}$ transplantation experiments and conducted the FVIII assay and functional tests. PB contributed to histopathology of liver. PN contributed to macroscopic examination of systemic allo-reactions and interpretation of results. AM contributed to conception and design and to manuscript writing. All authors read and approved the final manuscript.

\section{Acknowledgments}

The authors thank Vikash Kumar for providing technical assistance in flow cytometry-based studies and Kapil Manglani for acquiring images in confocal microscope. The last author is grateful to Director, National Institute of Immunology, for providing financial support to the work.

\section{Author details}

${ }^{1}$ Stem Cell Biology Laboratory, National Institute of Immunology, Aruna Asaf Ali Marg, New Delhi 110067, India. ${ }^{2}$ Experimental Animal Facility, National Institute of Immunology, New Delhi, India.

Received: 17 March 2015 Revised: 19 May 2015

Accepted: 25 June 2015 Published online: 08 July 2015

\section{References}

1. Shahani T, Covens K, Lavend'homme R, Jazouli N, Sokal E, Peerlinck K, et al. Human liver sinusoidal endothelial cells but not hepatocytes contain factor VIII. J Thromb Haemost. 2014;12:36-42.

2. Fahs SA, Hille MT, Shi Q, Weiler H, Montgomery RR. A conditional knockout mouse model reveals endothelial cells as the principal and possibly exclusive source of plasma factor VIII. Blood. 2014;123:3706-13.

3. Everett LA, Cleuren AC, Khoriaty RN, Ginsburg D. Murine coagulation factor VIII is synthesized in endothelial cells. Blood. 2014;123:3697-705.

4. Montgomery RR, Shi Q. Alternative strategies for gene therapy of hemophilia. Hematology Am Soc Hematol Educ Program. 2010:2010:197-202.

5. Du LM, Nurden P, Nurden AT, Nichols TC, Bellinger DA, Jensen ES, et al. Platelet-targeted gene therapy with human factor VIII establishes haemostasis in dogs with haemophilia A. Nat Commun. 2013;4:2773.

6. Matsui H, Fujimoto N, Sasakawa N, Ohinata Y, Shima M, Yamanaka S, et al. Delivery of full-length factor VIII using a piggyBac transposon vector to correct a mouse model of hemophilia A. PLoS One. 2014;9:e104957.

7. Ye P, Thompson AR, Sarkar R, Shen Z, Lillicrap DP, Kaufman RJ, et al. Naked DNA transfer of Factor VIII induced transgene-specific, species-independent immune response in hemophilia A mice. Mol Ther. 2004;10:117-26

8. Follenzi A, Benten D, Novikoff P, Faulkner L, Raut S, Gupta S. Transplanted endothelial cells repopulate the liver endothelium and correct the phenotype of hemophilia A mice. J Clin Invest. 2008:118:935-45.

9. Lagasse E, Connors H, Al-Dhalimy M, Reitsma M, Dohse M, Osborne L, et al. Purified hematopoietic stem cells can differentiate into hepatocytes in vivo. Nat Med. 2000;6:1229-34

10. Muraca M, Ferraresso C, Vilei MT, Granato A, Quarta M, Cozzi E, et al. Liver repopulation with bone marrow derived cells improves the metabolic disorder in the Gunn rat. Gut. 2000;56:1725-35.

11. Chen $H L$, Wang $R$, Hwu WL, Jeng $Y M$, Chang $M H$, Ling V. Bone marrow transplantation results in donor-derived hepatocytes in an animal model of inherited cholestatic liver disease. J Biomed Sci. 2000;15:615-22.

12. Yadav N, Kanjirakkuzhiyil S, Kumar S, Jain M, Halder A, Saxena R, et al. The therapeutic effect of bone marrow-derived liver cells in the phenotypic correction of murine hemophilia A. Blood. 2009;114:4552-61.

13. Li XC, Turka LA. An update on regulatory T cells in transplant tolerance and rejection. Nat Rev Nephrol. 2010;6:577-83.

14. Roy S, Javed S, Jain SK, Majumdar SS, Mukhopadhyay A. Donor hematopoietic stem cells confer long-term marrow reconstitution by self-renewal divisions exceeding to that of host cells. PLOS ONE. 2012;7:e50693.

15. Seglen P. Preparation of isolated rat liver cells. Meth Cell Biol. 1976;13:29-83.

16. El-Hayek JM, Rogers TE, Brown GR. The role of TNF in hepatic histopathological manifestations and hepatic CD8 ${ }^{+} \mathrm{T}$ cell alloresponses in murine MHC class I disparate GVHD. J Leukoc Biol. 2005;78:1001-7.
17. Bi L, Sarkar R, Naas T, Lawler AM, Pain J, Shumaker SL, et al. Further characterization of Factor VIII-deficient mice created by gene targeting: RNA and protein studies. Blood. 1996:88:3446-50.

18. Bumgardner GL, Orosz CG. Unusual patterns of alloimmunity evoked by allogeneic liver parenchymal cells. Immunol Rev. 2000;174:260-79.

19. Coppola A, Di Capua M, Dario MN, Di Palo M, Marrone E, lerano P, et al. Treatment of hemophilia: a review of current advances and ongoing issues. J Blood Med. 2010;1:1183-95.

20. Oldenburg J. Optimal treatment strategies for hemophilia: achievements and limitations of current prophylactic regimens. Blood. 2015;125:2038-44

21. Bardi E, Astermark J. Genetic risk factors for inhibitors in haemophilia A. Eur J Haematol. 2015;94:7-10.

22. Sanada C, Kuo CJ, Colletti EJ, Soland M, Mokhtari S, Knovich MA, et al. Mesenchymal stem cells contribute to endogenous FVIII production. J Cell Physiol. 2013;228:1010-6.

23. Follenzi A, Raut S, Merlin S, Sarkar R, Gupta S. Role of bone marrow transplantation for correcting hemophilia $\mathrm{A}$ in mice. Blood. 2012:119:5532-42.

24. Yadav N, Kanjirakkuzhiyil S, Ramakrishnan M, Das TK, Mukhopadhyay A. Factor VIII can be synthesized in hemophilia A mice liver by bone marrow progenitor cell-derived hepatocytes and sinusoidal endothelial cells. Stem Cells Dev. 2012:21:110-20.

25. Barthelmes D, Irhimeh MR, Gillies MC, Zhu L, Shen W. Isolation and characterization of mouse bone marrow-derived Lin(-)NEGF-R2(+) progenitor cells. Ann Hematol. 2013;92:1461-72.

26. Harb R, Xie G, Lutzko C, Guo Y, Wang X, Hill CK, et al. Bone marrow progenitor cells repair rat hepatic sinusoidal endothelial cells after liver injury. Gastroenterology. 2009;137:704-12.

27. DeLeve LD. Liver sinusoidal endothelial cells and liver regeneration. J Clin Invest. 2013;123:1861-6.

28. Ma S, Xie N, Li W, Yuan B, Shi Y, Wang Y. Immunobiology of mesenchymal stem cells. Cell Death Differ. 2014;21:216-25.

29. Newsome PN, Johannessen I, Boyle S, Dalakas E, McAulay KA, Samuel K, et al. Human cord blood-derived cells can differentiate into hepatocytes in the mouse liver with no evidence of cellular fusion. Gastroenterology. 2003;124:1891-900

30. Jang YY, Collector MI, Baylin SB, Diehl AM, Sharkis SJ. Hematopoietic stem cells convert into liver cells within days without fusion. Nat Cell Biol. 2004;6:532-9.

31. Wang $X$, Willenbring $H$, Akkari $Y$, Torimaru $Y$, Foster $M$, Al-Dhalimy $M$, et al Cell fusion is the principal source of bone-marrow-derived hepatocytes. Nature. 2003;422:897-901.

32. Vassilopoulos G, Wang PR, Russell DW. Transplanted bone marrow regenerates liver by cell fusion. Nature. 2003;422:901-4.

33. Alvarez-Dolado M, Pardal R, Garcia-Verdugo JM, Fike JR, Lee HO, Pfeffer K, et al. Fusion of bone-marrow-derived cells with Purkinje neurons, cardiomyocytes and hepatocytes. Nature. 2003;425:968-73.

34. Duncan AW, Hickey RD, Paulk NK, Culberson AJ, Olson SB, Finegold MJ, et al. Ploidy reductions in murine fusion-derived hepatocytes. PLoS Genet. 2009:5:e1000385.

35. Matsui H, Shibata M, Brown B, Labelle A, Hegadorn C, Andrews C, et al. A murine model for induction of long-term immunologic tolerance to factor VIII does not require persistent detectable levels of plasma factor VIII and involves contributions from Foxp3+ T regulatory cells. Blood. 2009;114:677-85.

36. Miao CH, Harmeling BR, Ziegler SF, Yen BC, Torgerson T, Chen L, et al. CD4 + FOXP3+ regulatory $T$ cells confer long-term regulation of factor VIIIspecific immune responses in plasmid-mediated gene therapy-treated hemophilia mice. Blood. 2009;114:4034-44.

37. Peng $B$, Ye $P$, Rawlings $A$, Ochs $H D$, Miao CH. Anti-CD3 antibodies modulate anti-factor VIII immune responses in hemophilia A mice after factor VIII plasmid-mediated gene therapy. Blood. 2009;114:4373-82.

38. Joffre O, Santolaria T, Calise D, Al Saati T, Hudrisier D, Romagnoli P, et al. Prevention of acute and chronic allograft rejection with CD4 + CD25 + Foxp3+ regulatory T lymphocytes. Nat Med. 2008;14:88-92.

39. Adeegbe D, Levy RB, Malek TR. Allogeneic T regulatory cell-mediated transplantation tolerance in adoptive therapy depends on dominant peripheral suppression and central tolerance. Blood. 2010;115:1932-40.

40. Davies JD, Leong LY, Mellor A, Cobbold SP, Waldmann H. T cell suppression in transplantation tolerance through linked recognition. J Immunol. 1996;156:3602-7. 
41. Waldmann H. Tolerance can be infectious. Nat Immunol. 2008;9:1001-3.

42. Wang $\mathrm{H}$, Xu J, Ji X, Yang X, Sun K, Liu X, et al. The abnormal apoptosis of T cell subsets and possible involvement of IL-10 in systemic lupus erythematosus. Cell Immunol. 2005;235:117-21.

43. Estaquier J, Marguerite M, Sahuc F, Bessis N, Auriault C, Ameison JC. Interleukin-10-mediated T cell apoptosis during the T helper type 2 cytokine response in murine Schistosoma mansoni parasite infection. Eur Cytokine Netw. 1997;8:153-60

Submit your next manuscript to BioMed Central and take full advantage of:

- Convenient online submission

- Thorough peer review

- No space constraints or color figure charges

- Immediate publication on acceptance

- Inclusion in PubMed, CAS, Scopus and Google Scholar

- Research which is freely available for redistribution 